\title{
О редких и эндемичных видах растений Боралдайтау
}

\section{About rare and endemic species of plants Boraldaytau}

\author{
Курмантаева А. А., Данилов М. П., Шорманова А. А. \\ Kurmantayeva A. A., Danilov M. P., Shormanova A. A. \\ Институт ботаники и фитоинтродукиии КН МОН РК, г. Алматы, Республика Казахстан. E-mail.ru: kurmanalfia@mail.ru \\ Institute of Botany and phytointroduction of the Committee of Science of the Ministry of Education \\ and Science of the RK, Almaty, Kazakhstan
}

\begin{abstract}
Peферат. В статье приводится точное местонахождение и границы ареалов некоторых редких и эндемичных видов гор Боралдайтау. Редкие и эндемичные виды рассматриваются в объеме четырех групп, выделенных по уровню необходимой охраны.
\end{abstract}

Ключевые слова. Ареал, Боралдайтау, границы распространения, редкий вид, субэндемик, Сырдарьинский Каратау, эндемик.

Summary. The article provides the exact location and boundaries of the ranges of some rare and endemic species of the Boraldaytau Mountains. Rare and endemic species are considered joining in four groups, identified by the level of necessary protection.

Key words. Area, Boraldaytau, borders of distribution, rare species, subendemic, Syrdarya Karatau, endemic.

Хребет Боралдайтау - одна из горных систем юго-восточной части Сырдарьинского Каратау. С севера расположен хр. Каратау, а южнее - горы Таласского Алатау, Угамского хребта и Каржантау. Про-

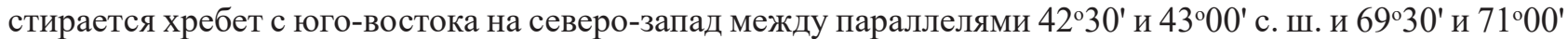
в. д. Исследуемый участок включает в себя особо охраняемые природные территории (ОППТ): Сырдарья-Туркестанский государственный региональный природный парк и Сайрам-Угамский государственный национальный природный парк.

Выявление редких и эндемичных видов во флоре Боралдайтау выполнено в рамках грантового проекта «Современное состояние редких, эндемичных и находящихся под угрозой исчезновения видов растений во флоре Боралдайтау» и является результатом трехлетнего (2015-2017 гг.) изучения флоры.

Полевые исследования, обзор региональных Красных книг (Красная книга ..., 1981, 2002, 2014), анализ хорологических, морфологических, биологических и экологических особенностей дали возможность для обоснования выделения редких и эндемичных видов, внесенных в Красные книги: 23 вида в Красную книгу Казахстана, 8 видов в Красную книгу Южно-Казахстанской области. Три вида - Juniperus seravschanica Kom, Pistacia vera L., Celtis caucasica Willd. - широко распространены, но редкие в Казахстане. Два реликтовых вида - Rhaphidophyton regelii Bunge Iljin (Chenopodiaceae), Spiraeanthus srhrenkianus Maxim. (Rosaceae) - являются представителями монотипных родов.

Редкие и эндемичные виды рассматриваются в объеме четырех групп (A, B, C, Д) выделяемых по уровню необходимой охраны (Жапарова, 2001; Иващенко, 2003, 2015).

В состав группы А включены виды, подлежащие государственной охране. В Красной книге Казахстана (Красная книга ..., 2014) для каждого вида приведена одна из категорий, принятых Комиссией по редким и исчезающим видам Международного союза охраны природы и природных ресурсов (МСОП):

3(R) - сокращающиеся: виды, численность которых сокращается, а ареал сужается в течение времени по естественным причинам, либо из-за вмешательства человека. Необходим контроль за их состоянием в местах естественного произрастания. В эту категорию вошли 14 видов: Juniperus 
seravschanica, Arum korolkowii Regel, Eminium lehmanni (Bunge) O. Kuntze, Tulipa alberti Regel, Tulipa greigii Regel, Tulipa kaufmanniana Regel и др.

2(U) - редкие виды, подвергшиеся прямой угрозе исчезновения, но встречающиеся в таком небольшом количестве, что они могут быстро исчезнуть. Выделены 10 видов: Juno coerulea Poljak, Juno orchioides (Carr.) Vved., Crocus alatavicus Regel et Semen., Celtis cancasica и др.

$1 \mathrm{E}$ - находящиеся под угрозой: дальнейшее существование этих видов невозможно без осуществления специальных мер охраны - Haplophyllum eugenii кorovinii Pavl., Tulipa orthopoda Vved., Pyrus regelii Rehd., Calophaca tianschania (B. Fedtsch.) Boriss, Lepidolopha filifolia Pavl.

4 (I) - неопределенный: вид, возможно, находящийся под угрозой исчезновения - Valeriana chionophila M. Pop.et Kult.

Значительным числом видов представлена группа В - виды, рекомендуемые к региональной охране (в пределах области): Korolkowia sewerzowii Regel, Tulipa orthopoda, Eremurus lactiflorus O. Fedtsch., Allium longicuspus Regel, Pyrus regelii, Calophaca tianschanica, Cousinia alberti Regel et Schmalh., Lepidolopha filifolia Pavl.

В группу С вошли виды, рекомендуемые к охране в местах произрастания. В число этой группы вошли редкие и эндемичные виды исследуемой территорий: Leymus aemulans (Nevski) Tzvel., Allium drobovii Vved., Astragalus sisyrodites Bunge, Scutellaria androssovii Juz., Thymus karatavicus A.Dmitr. ex Gamajun., Pedicularis karatavica Pavl., Bungea vesiculifera (Herd.) Pavl. et Lipsch., Acantholimon squarrosum Pavl., Artemisia karatavica Krasch. et Abol. ex Poljak., Cousinia minkwitziae Bornm. Рассмотренные виды подвергаются прямой угрозе исчезновения и встречаются в таком небольшом количестве, что они могут быстро исчезнуть. Сохранение этих растений возможно при присоединении мест их произрастания к охраняемым территориям.

Группу D составляют виды, следующие по уязвимости за находящимися под угрозой исчезновения. В настоящее время эти виды не являются предметом охраны, однако требуют дальнейшего наблюдения за их состоянием в местах произрастания: Juniperus sabina L., Eremurus regelii Vved., Scilla pusckinioides Regel, Polygonatum sewerzowii Regel, Rheum maximowiczi Losinsk., Dianthus karataviensis Pavl. ex Schischk., Dianthus kuschakewiczii Regel et Schmalh., Silene kuschakewiczii Regel et Schmalh., Achoriphragma asperrimum B.Fedtsch.Sojak, Crataegus pontica C. Koch, Meristotropis triphylla (Fisch. et C. A. Mey.) Fisch. et C. A. Mey, Ferula karatavica Regel et Schmalh., Schrenkia congesta Korov., Bunium vaginatum Korov., Scutellaria immaculata Nevski ex Juz., Cylindrocarpa sewerzowii (Regel) Regel, Sergia sewerzowii (Regel) Fed., Artemisia porrecta Krasch. et Abol. ex Poljak., Pyrethrum pyrothroides (Kar. et Kir.) B. Fedtsch. ex Krasch., Erigeron leucophyllus (Bunge) Boiss. Для этих видов Каратау является северной границей ареала.

В ходе полевых исследований было отмечено, что наибольшая концентрация редких видов находится в западной и восточной части хр. Боралдайтау. Ботаническую ценность в западной части (N:4251'40.4", E: 6952'05.1"), на высоте 553-773 м над ур. м. представили следующие географические точки: ущелья Теректы, Байкалмак, Кайнау, Туттисай, гора Улькентура, долина р. Борадай, урочище Костура. В ущелье Теректы (N:430'29", E:7000'47"), на высоте 858 м на мелкоземистом склоне отмечается местонахождение редких видов: Eremurus regelii, Scilla pusckinioides, Meristotropis triphylla, Polygonatum sewerzowii, Rheum maximowiczi. Встречается единично Artemisia porrecta в ущелье Байкалмак, гора Каратас (N:425126", E:694915", h 582 м).

Ботаническую ценность в восточной части Боралдайтау представляет ущелье Кокбулак в Южно-Казахстанской области, Тюлькубасском районе (N: 42 40'27.9", E: 70 15'23.2", h 830-836 м над), на территории Сайрам-Угамского национального парка. Ущелья Коныртобе, Шакпак, Карикорган, гора Бокейтау (N:4240'10.8", E:70²4'38.9") расположены в Жамбылской области, Жуалинском районе на неохраняемой территории. Высотные отметки находятся в пределах 1250-1363 м над ур. м. Наибольший интерес представили редкие виды, произрастающие на самой высокой вершине Боралдайтау, на горе Бокейтау (N:4241'47.6", E: 70²0'38.4", h 1356 м). Здесь отмечается точное местонахождение редких видов: Juniperus sabina L., Achoriphragma asperrimum, Sergia sewerzowii, Cylindrocarpa sewerzowii, Erigeron leucophyllus, Pyrethrum pyrothroides. Эти виды были найдены лишь в одной точке, следует отметить, что нужны дальнейшие наблюдения за их состоянием в местах произрастания. 
В результате ареалогического анализа, проведенного на основе имеющихся данных о современных боролдайских представителях (17 видов) эндемичных видов, нами выявлены 4 типа ареалов, которые объединяются в 2 группы: Турано-пригорнотяньшанскую и Каратауско-западнотяньшанскую. Типы ареалов выделены согласно общим принципам (касающимся всех высших растений), изложенным в работах А. И. Толмачева (1962), Р. В. Камелина (1973), 3. В. Карамышевой и Е. И. Рачковской (1973), Н. К. Аралбаев (Аралбаев, 2002). Туранский тип ареала объединяет виды, распространенные как в южных, так и в северных пустынях Турана (Лавренко, 1962).

Турано-пригорнотянышанская группа включает 4 вида: Tulipa alberti, Tulipa greigii, Spiraeanthus srhrenkianus, Meristotropis triphylla. Эти виды распространены не только в пустыняхТурана и в горных системах Средней Азии, но и на ее предгорных территориях. Вид Tulipa alberti встречается в Сырдарьинском Каратау, Чу-Илийских горах, в южной части Бетпакдалы, Прибалхашье (Таргыл), в юго-западных отрогах Джунгарского Алатау. Везде, кроме Чу-Илийский гор, встречается редко (Иващенко, 2005). Собрано в Боралдайтау: ущелье Теректы (N: 4300'29", E: 7000'47", h 858 м); правый берег Узун Кокбулака (N: 4240'15.5", E:70¹5'.6", h 830 м). Tulipa greigi занимает территории от северных пустынь (окр. Кызылорды) по горам и шлейфам Тянь-Шаня до перевала Курдай (Жамбылская, Южно-Казахстанская и Кызылординская области), Каржантау, Таласский Алатау, Угамский; Киргизский Алатау, Чу-Илийские горы. За пределами республики - Чаткальский хребет, Ташкентский Алатау, Киргизский Алатау (Иващенко, 2015). Вид нами отмечается повсеместно на сероземах и каменистых склонах горы Боралдайтау. Spiraeanthus srhrenkianus из монотипного рода встречается в юго-восточной части хребта Сырдарьинского Каратау, центральной и западной части Бетпакдалы. В Казахстане таволгоцвет древовидной формы изредка встречается только в ущельх юго-западных склонов Каратау (Красная книга ..., 2014). Собрано в Боралдайтау: ущелье Байкалмак, по правому берегу р. Боролдай, терраса, переходящая в пологий горный склон (N: 4252'07.09", E: 6952'24.04", h 573 м); ущелье Туттибулак, левобережье бассейна р. Боралдая (N: 4251'40.4", E: 69 52'05.1", h553 м). Meristotropis triphylla встречается в Чу-Илийских горах, Сырдарьинском Каратау и Западном Тянь-Шане. Собрано в Боралдайтау: урочище Костура, скалы между двух гор по правому берегу р. Боралдая (N: 42 $52^{\prime} 03.0^{\prime \prime} \mathrm{E}: 7^{\circ}$ 03'06.5" h 762 м).

Каратауско-западнотяньшанская группа объединяет следующие типы ареалов: Каратауский, Каратаускозападно-тяньшанский, Каратауско-талаский, Восточнокаратауско-западнотяньшанский. Каратауский тип ареала включают виды, ограниченные в своем распространении хребтом Каратау. Данный тип ареала подразделяется н аподтипы: собственно Каратауский, Боралдайский и Восточнокаратауский.

Собственно каратауский подтип включает виды: Leymus aemulans, Rhaphidophyton regelii, Astragalus karataviensis, Haplophyllum Eugenii Korovinii, Artemisia karatavica. Боролдайский подтип представлен одним видом Lepidolopha karatavica. Собрано в Боралдайтау: горы Кулантау, нижняя часть склона, боярышниковое редколесье (42037.19.5" с. ш., 70024.07.1"в. д., h 1070 м); ущелье Кокбулак, злаково-разнотравное сообщество (42041.41.7" с. ш., 70⒛38.0"в. д., h 1417 м), гора Бокейтау. Восточнокаратауский подтип ареала включает Cousinia alberti. Вид встречается в восточной части Каратау, только в районе Машат-Даубабинских и Боралдайских гор. Собрано в Боралдайтау: ущ. Теректы (N: 4300'29", E: 7000'47", h 858 м); правый берег Узун Кокбулака (N: 42²4'15.5", E: 70¹5'.6", h 830 м).

Каратауско-западнотяньшанский тип ареала характерен для видв Astragalus sisyrodites, Thymus karatavicus. Эти виды встречаются в Каратау и широко распространены в горных системах Западного Тянь-Шаня (Таласский Алатау, Каржантау, Угамский, Пскемский, Чаткальский, Кураминский и др. хребты). Местонахождение вида Astragalus sisyrodites в Боралдайтау отмечается в ущ. Теректы (N: 4300'29", E: 7000'47", h 858 м); хр. Таласский Алатау, у подножья склона горы Барсук-саю (01 I 1935, А. Дмитрева); хр. Каржантау (22 V 1931, Н. В. Павлов). Вид Thymus karatavicus в Боралдайтау отмечается в ур. Костура, скалы между двух гор по правому берегу р. Боралдая (южный каменистый склон) (4251'58.6" с. ш., 70 02'59.7" в. д., h 794). Встречается в Таласском Алатау, в Машаттау на мелкоземисто-щебнистом северо-западном склоне (23 VI 1973, Н. Х. Кармышева); хр. Каржантау, ущ. Наут напротив с. Каскасу (25 VII 1958, Н. Х. Кармышева). 
Каратауско-таласский тип ареала характерен для видов, распространенных в Каратау и проникающих в хр. Таласский Алатау: Bunium vagitatum, Tulipa orthopoda, Allium drobovi. В восточной части Каратау концентрация видов прослеживается в его юго-западных и юго-восточных частях и в районе Машат-Даубабинских гор. Bunium vagitatum - хр. Таласский Алатау, каменистые склоны Сас-тюбе (01 I 1935, А. Дмитриева). Собрано в Боралдайтау: Жамбылская обл., Жуалинский район, правобережье бассейна р. Боралдай (N: 4248'36.3", E: 70²15'52.6", h 1256 м). Tulipa orthopoda - центральная часть хр. Каратау и в Таласском Алатау. Собрано в Боралдайтау: ущ. Теректы (N: 4300'29", E: 7000'47", h 858 м). Allium drobovi - юго-западные отроги Таласского Алатау на каменисто-щебнистых склонах (01 I 1935, А. Дмитрева). Собрано в Боралдайтау: ущелье Теректы (N: 4300'29", E: 7000'47", h 858 м).

Восточнокаратауско-таласский тип ареала охватывает восточную часть Каратау и проникает в Таласский Алатау. Этот тип ареала представлен C. minkwitziae. Ареал вида занимает восточную часть Каратау, далее проходит в только в западную часть Таласского Алатау. Собрано в Боралдайтау: хр.

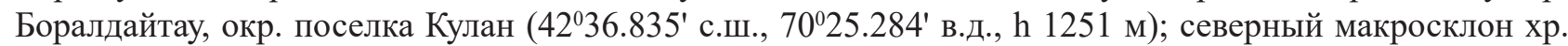
Машаттау (42³0.144' с.ш., 7008.385' в.д., h 1035 м); хр. Боралдайтау, окр. с. Коныртобе (4241.079' с.ш., 70²4.951' в.Д., h 1251 м); южный склон хр. Машаттау, окр. лагеря «Юбилейный» (Фисташниковое редколесье), на шлейфах с осыпями (42²5.494' с.ш., 7000.993' в.д., h 990 м); хребет Машаттау (пырейно-ячменная полусаванна) (42²7.631' с.ш., 7005.142' в.д., h 907 м); в восемнадцати километрах южнее с. Даубаба, место стоянки скота (сорная растительность), долина реки Машат (42²2.075' с.ш., 70¹1.593' в.Д., h 1185 м); восточная оконечность хр. Каратау, в полуторах километрах западнее пос.

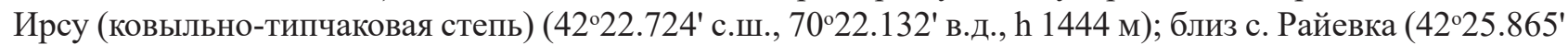
с.ш., 70²2.802' в.д., h 1362 м); хр. Машаттау, с. Даубаба (42²5.990' с.ш., 70¹1.522' в.д., h 1174 м).

Таким образом, на исследуемой территории выделены 4 типа ареала, где отмечены местонахождения 17 эндемичных видов, и 10 из них являются субэндемичными для Каратау. Субэндемичные виды встречаются в пределах Каратау и Западного Тянь-Шаня. Эта группа ареалов отражает определенные особенности распространения Боролдайских (каратауских) эндемичных видов. Эндемичные и субэндемичные виды в Боралдайтау представлены более разнообразными типами и количеством видов. Вероятно, именно эта группа отражает закономерности географического распространения видов.

Итак, горы Боралдайтау являются северной границей ареала для видов из Каратауско-западнотяньшанской группы:

- Lepidolopha karatavica с Боролдайским подтипом ареала,

- Cousinia alberti с Восточнокаратауским подтипом ареала,

- C. minkwitziae с Восточнокаратауско-западнотяньшанским типом ареала.

Сырдарьинский Каратау является северной границей для редких видов: Scilla puschkinioides Regel, Ferula karatavica Regel et Schmalh., Artemisia porecta Krasch. ex Poljak, Scutellaria immaculata Nevski ex Juz., Bungea vesiculifera (Herd ) Pavl. et Lipsch. ,Cousinia pseudomollis C. Winkl., Lepidolopha komarowii C.Winkl., Erigeron amorphoglosus Boiss., Dianthus karataviensis Pavl. ex Schischk., Cylindrocarpa sewerzowii (Regel), Pistacia vera L., Schrenkia congesta Korov.

Мы рекомендуем внести в Красную книгу Казахстана Crataegus pontica, находящийся в Боралдайтау на пределе своего ареала. Этот вид формирует уникальное сообщество, создает среду обитания для других видов растений и имеет узкую локализацию в пределах Южного Казахстана. На территории Боралдайтау ареал его распространения ограничивается. Предлагаем организовать заказник в восточной части хребта (гора Бокейтау) либо присоединить этот участок к охраняемой территории (Аксу-Джабаглинский заповедник) для охраны вида вместе с другими редкими и исчезающими растениями.

Учитывая интенсивное освоение исследуемой территорий, список охраняемых растений в дальнейшем может быть существенно пополнен. Кроме того, требуют особого учета эндемики и редкие виды растений, находящиеся на границе своего географического распространения. 


\section{ЛИТЕРАТУРА}

Аралбаев Н. К. Очерк флоры или о фитохорологическом статусе Сырдарьинского Каратау (Материалы к флористическому районированию Казахстана) //Экологические поблемы Туркестанского региона: материалы междунар. эколог. конф. - Туркестан, 2002. - С. 215-218.

Жапарова Н. К. О редких сообществах Сырдарьинского Каратау // Геоботанические исследования в семиаридных и аридных регионах: современное состояние, проблемы и перспективы: материалы междунар. конф. (1012 мая 2001 г.). - Алматы, 2001. - С. 60-62.

Иващенко А. $\boldsymbol{A}$. О некоторых новых и редких растениях Сырдарьиского Каратау // Ботанические исследования в Казахстане: материалы научн. конф. - Алматы, 2003. - С. 57-62.

Иващенко A. A. Тюльпаны и другие растения Казахстана. - Издана при финансовой поддержке Shell Kazakhstan Develoipmtnt B.V., 2005. -53 c.

Иващенко $\boldsymbol{A}$. $\boldsymbol{A}$. Список охраняемых территорий Боралдайтау // Ботан. иссл. Сибири и Казахстана: сборн. научн. трудов. / Под ред. А. Н. Куприянова. - Кемерово: КРЭОО "Ирбис", 2015. - Вып. 21. - С. 86-93. Камелин P. B. Флорогенетический анализ естественной флоры горной Средней Азии. - Л., 1973. - 354 с.

Карамымева 3. В., Рачковская $\boldsymbol{E}$. И. Ботаническая география степной части Центрального Казахстана. - Л., 1973. - $279 \mathrm{c}$.

Лавренко Е. М. Основные черты ботанической географии пустынь Евразии и Северной Африки. - М.-Л., 1962. $-168 \mathrm{c}$.

Красная книга Казахской ССР. Редкие и находящиеся под угрозой исчезновения виды животных и растений. - Алма-Ата, 1981. - 260 с.

Красная книга Южно-Казахстанской области. Дикорастущие редкие и исчезающие виды растений. - Алматы, 2002. -148 c.

Красная книга Казахстана Т. 2. Ч. 2. - Институт ботаники и фитоинтродукции, 2014. - 446 с.

Толмачев А. И. Основы учения об ареалах (Введение в хорологию растений). - Л., 1962. - 156 с. 